\title{
Sobrevivência de Fusarium oxysporum f. sp. lycopersici Raça 2 submetido à técnica da solarização associada à incorporação de folhas de mandioca
}

\author{
Lina Chuan Wong ${ }^{1}$; Márcia Michelle de Queiroz Ambrósio²; Nilton Luiz de Souza ${ }^{3}$
}

${ }^{1}$ Centro de Energia Nuclear na Agricultura (CENA) - USP/ Laboratório de Biologia Celular e Molecular, Piracicaba-SP, 13416-000 Caixa Postal 96.; ${ }^{2}$ UFCG/CCTA/Unidade Acadêmica de Agronomia e Tecnologia de Alimentos, R. Cel. João Leite, 517, Cep. 58840-000, Pombal-PB; ${ }^{3}$ In memorian.

Autor para correnpondência: Lina Chuan Wong (lcwong17@gmail.com)

Data de chegada: 02/02/2009. Aceito para publicação em: 02/11/2010.

1631

\section{RESUMO}

Wong, L. C; Ambrósio, M. M. Q; Souza, N. L. Sobrevivência de Fusarium oxysporum f. sp. lycopersici Raça 2 submetido a técnica da solarização associada à incorporação de folhas de mandioca. Summa Phytopathologica, v.37, n.2, p.129-133, 2011.

A solarização combinada com a prévia adição de material orgânico propicia controle efetivo de diversos fungos de solo que de outra forma são de difícil erradicação, permitindo, também, redução do tempo de tratamento. O objetivo do trabalho foi avaliar o controle do fungo Fusarium oxysporum f. sp. lycopersici Raça 2, por meio da incorporação da parte aérea de mandioca brava (Manihot utilisima) e mandioca mansa (Manihot dulcis) seguido de solarização do solo. Foi realizado experimento de campo, onde incorporou-se $3 \mathrm{Kg} / \mathrm{m}^{2}$ da parte aérea de mandioca brava e mandioca mansa, separadamente. O experimento constou de seis tratamentos (solarização + mandioca brava; solarização + mandioca mansa; solo solarizado; solo; mandioca brava e mandioca mansa). A sobrevivência do fungo foi avaliado por meio das estruturas de resistência em meio semi-seletivo de Komada, aos 7, 14, 21 e 28 dias do início do experimento. As temperaturas do solo foram monitoradas através de um coletor de dados Tipo CR23X (Campbell Scientific) e a quantificação dos gases $\left(\mathrm{CO}_{2}\right.$ e $\left.\mathrm{O}_{2}\right)$ foi feita pelo equipamento analisador de gases (Testo 325-1). Nos tratamentos solarizados, a temperatura do solo e aprisionamento de $\mathrm{CO}_{2}$ foram maiores em relação à testemunha (solo) e aos tratamentos apenas com a incorporação de material vegetal. A associação da incorporação de mandioca, tanto a "brava" quanto a "mansa", com a solarização, proporcionou a inativação de $F$. oxysporum f.sp. lycopersici Raça 2, podendo atuar no controle da doença murcha de fusarium causada por este patógeno. Os demais tratamentos foram inócuos, permitindo a sobrevivência do fungo.

Palavras-chave adicionais: controle alternativo, decomposição acelerada, fungo fitopatogênico.

\section{ABSTRACT}

Wong, L. C; Ambrósio, M. M. Q. \& Souza, N. L. Survival of Fusarium oxysporum f. sp. lycopersici Race 2 subjected to the solarization technique associated with cassava leaves amendment. Summa Phytopathologica, v.37, n.2, p.129-133, 2011.

Soil solarization associated with organic matters provides an effective control of several soil-borne fungi, which are difficult to eliminate using other methods; in addition, this association shortens the treatment time. The aim of this study was to assess the control of Fusarium oxysporum f. sp. lycopersici Race 2 by combining the amendment of "bitter" cassava (Manihot utilisima) and "sweet" cassava (Manihot dulcis) leaves with soil solarization. A field experimental was carried out, $3 \mathrm{Kg} / \mathrm{m}^{2}$ of the two types of cassava leaves were separately amended. Six treatments were tested, (solarizated+ "bitter" cassava, solarizated+"sweet" cassava, soil solarizated, soil, "bitter"cassava and "sweet"cassava). Fungus control was assessed based on the survival resistance structures on semiseletive Komada medium at 7, 14, 21 and 28 days after the beginning of the experiment. Soil temperature values were monitored by a DataLogger Type CR23X (Campbell Scientific), and quantity of $\mathrm{CO}_{2}$ and $\mathrm{O}_{2}$ was monitored by a gas analyzer equipment (Testo 3251). In solarizated treatments, soil temperature and trapping of $\mathrm{CO}_{2}$ were higher than the control (soil) and treatments with organic material incorporated without solarization. The association of both "bitter" and "sweet" cassava amendment with soil solarization inatived the pathogen whereas the other treatments had no effect, allowing the survival of the fungus.

Keywords: alternative control, accelerated fermentation, soilborne phytopathogenic fungus

Patógenos habitantes do solo são um dos mais importantes problemas fitossanitários uma vez que apresentam estruturas de resistência que asseguram a sua sobrevivência em condições desfavoráveis. Para o controle de fungos veiculados pelo solo pode ser utilizada rotação de culturas o que já vem sendo usado há séculos (10) e tratamento químico como fungicidas (15). Apesar dos produtos químicos terem um amplo espectro de ação eles causam riscos ao ambiente e ao homem, além de provocar destruição na camada de ozônio, como é o caso do brometo de metila (14), que teve o seu emprego proibido em todo o mundo. A solarização (cobertura do solo úmido em pré- plantio, com um filme transparente de polietileno de baixa densidade, durante o período de maior radiação solar) (17) é uma alternativa de controle para muitos patógenos veiculados ao solo. É uma técnica que não utiliza agroquímicos e não deixa resíduos, além de 
ser um método simples e efetivo (22). Entretanto, para alguns fitopatógenos do solo, como o Fusarium oxysporum f. sp. lycopersici, na cultura do tomate, a temperatura atingida pela solarização não é suficiente para afetar a sua sobrevivência. A solarização associada com a adição de materiais orgânicos $(2,3,4,7,23,24,25)$ e de cama de frango $(5,13)$ tem mostrado resultados bastante promissores, além de ser uma prática ambientalmente segura (11). A solarização do solo combinada com a incorporação de materiais vegetais além da acumulação de calor (16) é atribuída à formação de compostos voláteis tóxicos e aumento da biota antagônica no solo $(3,21)$. A toxicidade da mandioca é causada pela presença de dois glicosídeos cianogênicos que são a linamarina e a lotaustralina metil (9) e segundo Bokanga (8), o potencial cianogênico das folhas da mandioca é 5 a 20 vezes maior que o das raízes.

Portanto o objetivo do presente consistiu em avaliar a sobrevivência de Fusarium oxysporum f. sp. lycopersici Raça 2 em solo incorporado com folhas de mandioca brava e mansa seguido de solarização e verificar se os dois materiais orgânicos possuem o mesmo potencial para inativação do fungo.

\section{MATERIAL E MÉTODOS}

O experimento foi realizado entre janeiro e fevereiro de 2006 na área experimental localizada na latitude $22^{\circ} 51^{\prime} \mathrm{S}$ e longitude $48^{\circ} 26^{\prime} \mathrm{W}$. Foi estudado o fungo fitopatogênico habitante do solo, Fusarium oxysporum f. sp. lycopersici Raça 2, agente causal de murcha em tomateiro. Este, proveniente da micoteca do DPV/FCA/UnespBotucatu-SP, foi cultivado em meio BDA (Batata-DextroseAgar)+oxitetraciclina $(0,05 \mathrm{mg} / \mathrm{mL})$ e posteriormente transferido para o substrato especifico, objetivando produzir as estruturas de resistências (clamidósporos).

A produção dos clamidósporos consistiu em multiplicar o fungo em meio líquido de extrato de malte, no escuro, a $25^{\circ} \mathrm{C}$ por 9 dias. Após o crescimento, a suspensão foi centrifugada a $3400 \mathrm{~g}$, por 30 minutos, e o precipitado ressuspendido em água destilada estéril. Em seguida, a suspensão foi colocada em bandeja de alumínio, acrescentando-se pó de talco na proporção de 2:1 (v/v) e deixando-se para secar em estufa com circulação forçada de ar, a $26^{\circ} \mathrm{C}$, durante 14 dias (7).

Foram utilizadas bolsas de tecido sintético (náilon), para acondicionar, as estruturas (clamidósporos) veiculadas em 15 gramas de pó de talco. Duas destas bolsas foram enterradas, a $10 \mathrm{~cm}$ de profundidade no solo da região central de cada uma das quatros parcelas, em todos os tratamentos. As unidades (bolsas) foram amarradas com linhas de náilon visando evitar o escape das estruturas, sendo deixada uma ponta da linha na superfície do solo para facilitar a localização e remoção.

Os materiais orgânicos estudados foram: mandioca brava (Manihot utilisima) e mandioca mansa (Manihot dulcis). A Tabela 1 mostra o resultado da análise dos materiais orgânicos. Após a coleta, os materiais orgânicos frescos foram triturados e imediatamente incorporados ao solo até a profundidade de $10 \mathrm{~cm}$ com o emprego de uma enxada rotativa, na proporção de $3 \mathrm{Kg} / \mathrm{m}^{2}$.

O experimento constou de seis tratamentos (Solo solarizado; solo desnudo; solo solarizado + folhas de mandioca brava; solo desnudo + folhas de mandioca brava; solo solarizado + mandioca mansa; solo desnudo + mandioca mansa), sendo cada um deles dividido em cinco parcelas de $6 \mathrm{~m}^{2}$, contendo em quatros delas duas repetições, representadas por bolsas veiculando as estruturas de resistência do fungo. Uma quinta parcela teve a função de receber os sensores de temperatura e as sondas para a avaliação dos gases.

Os sensores de temperatura, a $10 \mathrm{~cm}$ de profundidade, foram conectados a um coletor de dados Tipo CR23X (Campbell Scientific), para leitura a cada hora da temperatura, durante todo o transcorrer do experimento. Para a análise dos dados foram utilizadas as temperaturas máximas diárias. As sondas de gases foram instaladas próximas aos sensores de temperatura, instrumento desenvolvido por Souza \& Bueno (21), o qual possui um local de inserção da agulha do equipamento Texto 325-1 com dispositivo para a quantificação e registro impresso instantâneo de $\mathrm{O}_{2}$ e $\mathrm{CO}_{2}$. As leituras dos gases iniciaram-se no dia da instalação do experimento.

Após a colocação do patógeno e dos equipamentos no solo, prosseguiu-se a aplicação dos filmes de polietileno de baixa densidade, transparente e aditivado (aditivo anti-ultravioleta) de $4 \mathrm{~m}$ de largura e $100 \mathrm{~mm}$ de espessura nas parcelas pré-determinadas. Não houve a necessidade de irrigar a área uma vez que ocorreu precipitação nos dias imediatamente anteriores à instalação do experimento.

Foram realizadas aos 7, 14, 21e 28 dias após a instalação do experimento as coletas, nas parcelas de cada tratamento, das duas bolsas de náilon contendo estruturas do fungo, através de um corte na superfície do plástico, o qual, após a retirada das bolsas, foi vedado com uso de fita adesiva para evitar a volatilização dos gases e a perda da temperatura acumulada no solo, evitando, assim, qualquer interferência na parcela subseqüente.

O teste de sobrevivência das estruturas de resistências de $F$. oxysporum f. sp. lycopersici Raça 2 seguiu a metodologia modificada de Blok et al. (7). De cada bolsa contendo pó de talco + clamidósporos, foi retirada uma amostra de $10 \mathrm{~g}$, a qual foi submetida por diluições seriadas (quatro diluições) em solução salina $(0,05 \%)$. Foi mantida uma testemunha de laboratório que também passou pelo processo de plaqueamento. Alíquotas de todas as diluições $(100 \mu \mathrm{L})$ foram transferidas para cada uma de cinco placas contendo o meio semi-seletivo Komada (15g peptona; $1 \mathrm{~g} \mathrm{~K}_{2} \mathrm{HPO}_{4}$; $0,5 \mathrm{~g}$ $\mathrm{MgSO}_{4} .7 \mathrm{H}_{2} \mathrm{O} ; 20 \mathrm{~g}$ Agar; $0,25 \mathrm{~g}$ clorofenicol; $0,7 \mathrm{~g}$ PCNB; $1 \mathrm{~L}$ água destilada) (18), obtendo um total de 25 placas para cada uma das duas repetições (bolsas). As placas foram mantidas no escuro a

Tabela 1: Resultado da análise dos materiais orgânicos.

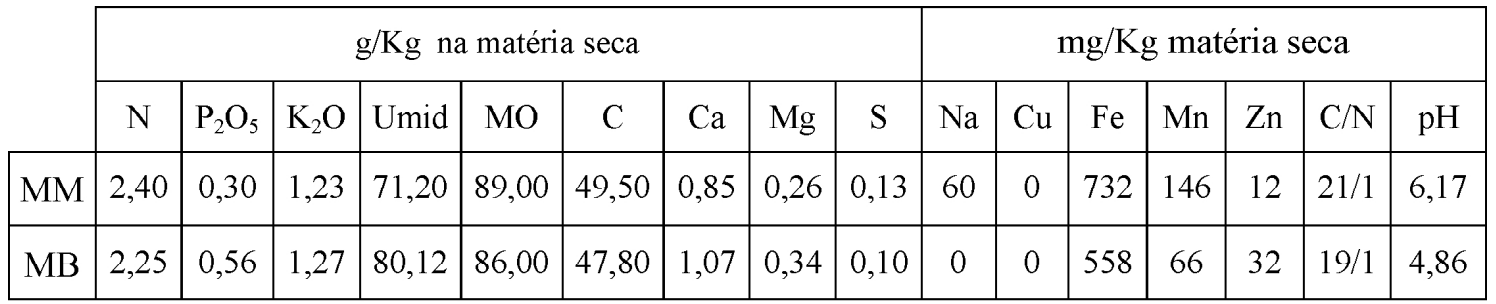

$\mathrm{MM}=$ Mandioca mansa

$\mathrm{MB}=$ Mandioca brava 
$26^{\circ} \mathrm{C}$ em BOD, passados 3 dias foi realizada a contagem das colônias desenvolvidas, pelo método direto.

\section{RESULTADOS E DISCUSSÃO}

A solarização promoveu um aumento da temperatura do solo em relação à testemunha absoluta (solo) e aos tratamentos onde apenas foi incorporado material orgânico (Figura 1).

Nos tratamentos solarizados, as temperaturas máximas diárias do solo a $10 \mathrm{~cm}$ de profundidade foram maiores nos tratamentos que incorporou materiais orgânicos previamente. A temperatura máxima diária do solo chegou a atingir $50^{\circ} \mathrm{C}$, quando foi incorporado material vegetal antes de solarizar (Figura 1). O material orgânico associado à solarização, possivelmente, contribuiu para o incremento dessa temperatura devido ao processo acelerado de decomposição.

O tratamento mandioca mansa+solarização foi o que promoveu maior temperatura do solo, a $10 \mathrm{~cm}$ de profundidade. A diferença de temperatura máxima diária em relação ao tratamento solarizado foi de aproximadamente $5^{\circ} \mathrm{C}$. Este dado também foi observado por Ambrósio et al. (2). De acordo com Gamliel \& Stapleton (12), solos incorporados com compostos orgânicos e solarizados aumentam a temperatura de 2 a $3^{\circ} \mathrm{C}$, comparando-se com aqueles apenas solarizados e esse aumento adicional pode ser importante fator no controle de organismos fitopatogênicos habitantes do solo.

A temperatura é de real importância no controle de fungos fitopatogênicos, pois tem efeito direto sobre os patógenos e, quando se incorporam compostos orgânicos, acelera a decomposição do material, propiciando a liberação de voláteis. Gamliel \& Stapleton (11), obtiveram controle de Pythium ultimum e $S$. rolfsii quando solarizaram à temperatura máxima de $45^{\circ} \mathrm{C}$, mas, quando a temperatura máxima atingiu somente $38^{\circ} \mathrm{C}$ o tratamento não foi eficiente. No entanto, quando a temperatura foi de $38^{\circ} \mathrm{C}$ e associou-se a solarização com incorporação prévia de resíduos de repolho, houve uma significativa redução na população desses patógenos no solo.

A porcentagemmédiadegases $\left(\mathrm{O}_{2}\right.$ e $\left.\mathrm{CO}_{2}\right)$ liberados (Figura 2) mostrou que houve aprisionamento do dióxido de carbono nos tratamentos onde aplicou-se a cobertura plástica, sendo que quando incorpou-se material orgânico, a porcentagem média de gás carbônico foi maior devido a decomposição dos resíduos vegetais. Ambrosio et al. (2) também detectaram maior liberação de $\mathrm{CO}_{2}$ nos tratamentos onde acrescentou-se materiais orgânicos e solarizou, quando comparado ao solo somente solarizado.

Nos tratamentos onde não foi aplicada a cobertura plástica, o oxigênio ficou em torno de $20 \%$ e praticamente todo o dióxido de carbono liberado pelos resíduos orgânicos incorporados ao solo foi volatilizado, possivelmente não atuando na sobrevivência das estruturas de resistência do patógeno. Em contra partida, com a solarização observou-se um decréscimo do $\mathrm{O}_{2}$ no solo, mais acentuado $(<5 \%)$ com a incorporação do material vegetal, resultado possível do metabolismo dos microorganismos decompositores.

A técnica de solarização do solo promove o aumento de temperatura do solo deste modo, o aquecimento acelera a decomposição dos materiais orgânicos liberando gás carbônico $\left(\mathrm{CO}_{2}\right)$ e baixas concentrações de $\mathrm{O}_{2}$ no solo (26) representam fator limitante para a germinação de microescleródios de determinados patógenos. Segundo Wyllie et. al. (26) concentrações abaixo de $16 \%$ de oxigênio, a viabilidade de Macrophomina phaseolina é prejudicada e o número de escleródios viáveis por grama de solo é menor em altas concentrações de gás carbônico e baixas de oxigênio, como ocorreu no presente trabalho.

Nos tratamentos onde apenas incorporou-se material orgânico e a testemunha absoluta (solo) não afetou a sobrevivência do fungo, mostrando que a aplicação do filme plástico é imprescindível para a inativação do patógeno. Em relação ao fungo mantido em laboratório, foi

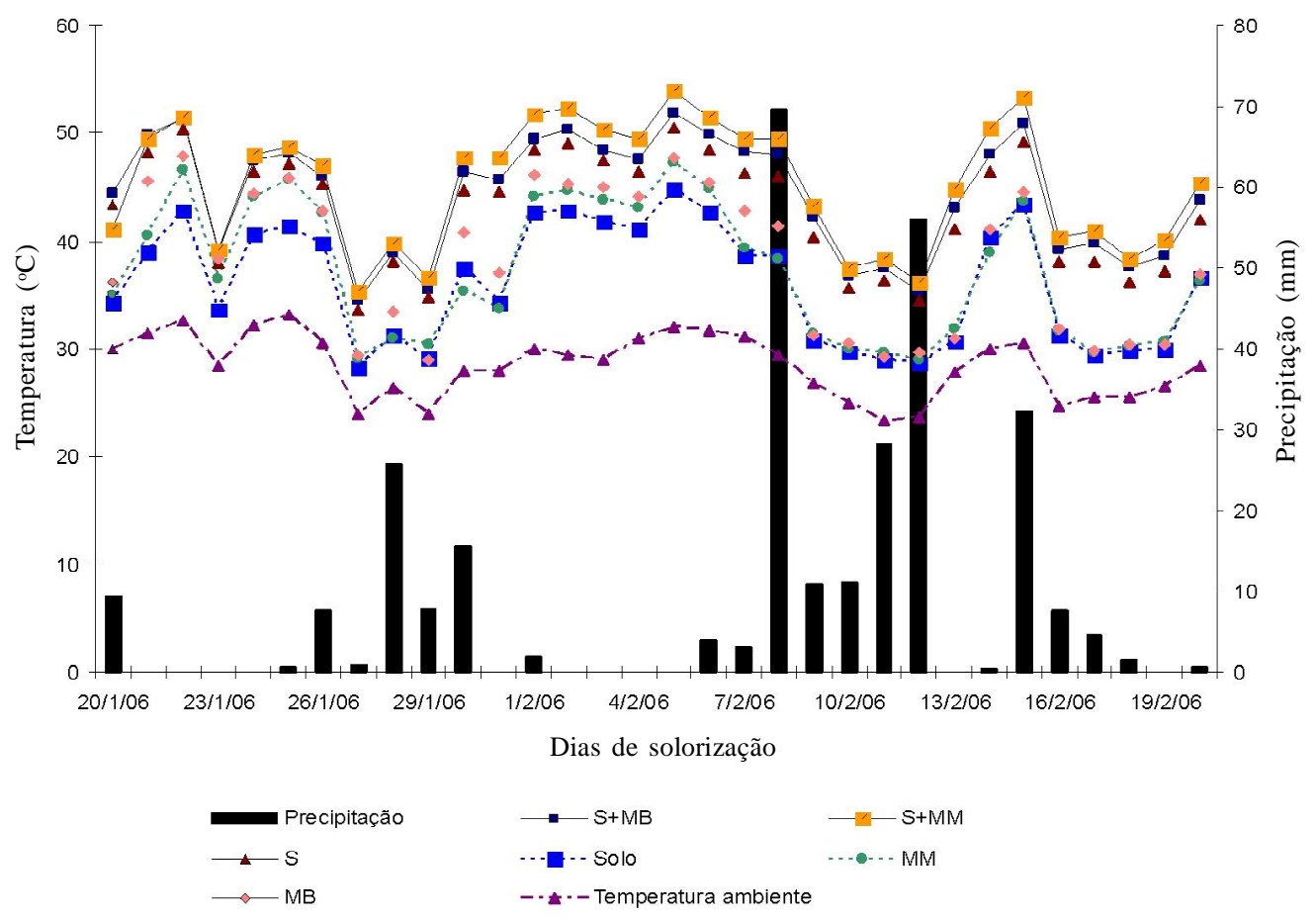

Figura 1. Temperaturas máximas diárias do solo a $10 \mathrm{~cm}$ de profundidade e precipitação, durante o experimento em campo. $\mathrm{S}=\mathrm{Solarizado}$; $\mathrm{MB}=$ Mandioca brava; $\mathrm{MM}=$ Mandioca mansa. 


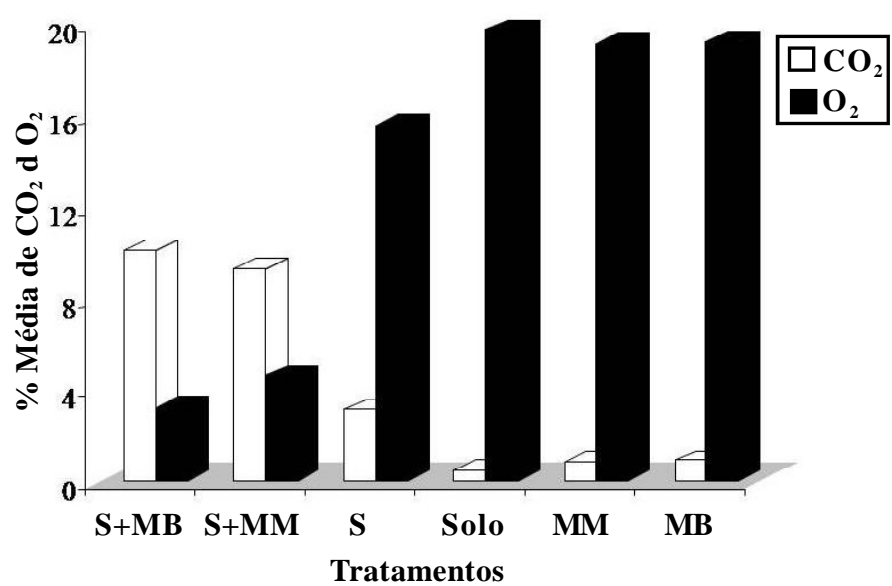

Figura 2. Porcentagem média de $\mathrm{O}$ e $\mathrm{CO}$ registrado durante o período de solarização. $\mathrm{S}=$ Solarizado; $\mathrm{MB} \stackrel{2}{=}$ Mañ2dioca brava; $\mathrm{MM}=$ Mandioca mansa.

verificada diminuição gradativa na sua sobrevivência fato esse também observado por Souza \& Bueno (25) e Ambrósio et. al. (1) (Figura 3).

Em todos os tratamentos em que associou-se a solarização com a incorporação do material orgânico, ocorreu a inativação de Fusarium oxysporum f. sp. lycopersici Raça 2 até o $7^{\circ}$ dia do experimento (Figura 3). É interessante destacar este período, pois é um dado importante, uma vez que demonstra a eficácia do tratamento representado pela solarização associada à incorporação de folhas de mandioca já aos sete dias após a instalação do ensaio. Esta completa inativação do patógeno representa um avanço, uma vez que o agricultor necessitará de apenas uma semana para o procedimento de erradicação de patógeno da área a ser cultivada.

O tratamento solarizado, de forma isolada, não foi eficiente no controle do patógeno (Figura 3). O fungo, F. oxyporum $\mathrm{f}$. sp. lycopersici Raça 2, é um patógeno bastante tolerante a altas temperaturas, e como já relatado por Sivan \& Chet (22), a solarização do solo por si só, não é suficiente para inativá-lo.

Blok et al., (7) mostraram que a cobertura plástica somente, não resulta numa redução significativa de propágulos viáveis de $F$. oxysporum f. sp. asparagi. Esses autores ressaltaram claramente o potencial da combinação da incorporação de material orgânico com a solarização na sobrevivência de vários patógenos de solo. Embora não tenham estudado o mecanismo de inativação do patógeno, os resultados obtidos indicaram que vários fatores contribuem para esta inativação, tais como a temperatura do solo, a anaerobiose (26) e os compostos específicos do material incorporado e explicam que a temperatura do solo, embora não seja suficiente para erradicar o fitopatógeno, é fundamental para o controle do fungo.

A adição de materiais orgânicos associados à solarização do solo tem sido apresentada como um avanço muito promissor para o controle de fitopatógenos do solo $(2,6)$. Entre os materiais vegetais mais pesquisados e empregados em conjunto com a solarização está as brássicas (7, 11, 21, 23). A associação, incorporação de brássicas mais solarização, tem afetado a sobrevivência de uma série de patógenos: $F$. oxysporum f. sp. conglutinans (21), Pythium ultimum e $S$. rolfsii (11), F. oxysporum f. sp. lycopersici, M. phaseolina, Pyrenochaeta terrestris, Pythium spp., R. solani (23).

Além das brássicas, existem outros materiais com potencial para serem utilizados em combinação com a solarização no controle de fitopatógenos habitantes do solo. Neste estudo foram avaliados dois materiais orgânicos: folhas de mandioca brava e de mandioca mansa e pode-se verificar que tanto os resíduos de mandioca brava como de mandioca mansa incorporados ao solo seguido de solarização mostraram-se tão eficientes quanto as brássicas no controle de $F$. oxyporum f. sp. lycopersici Raça 2 (2, 24). Diante disso, fica evidente que a utilização destes materiais, associados à solarização do solo, no controle de doenças de plantas é bastante conveniente. Além disso, a cultura de mandioca é encontrada em diversas regiões sendo fácil a sua obtenção.

Em mandioca brava, acredita-se que a atividade fungicida seja causada pela presença de dois glicosídeos cianogênicos, que são a linamarina, que participa em maior proporção (92-98\%), a lotaustralina metil, derivada da linamarina (2-8\%), e pela presença da enzima linamarase, que promove a hidrólise dos glicosídeos (9). O enxofre,

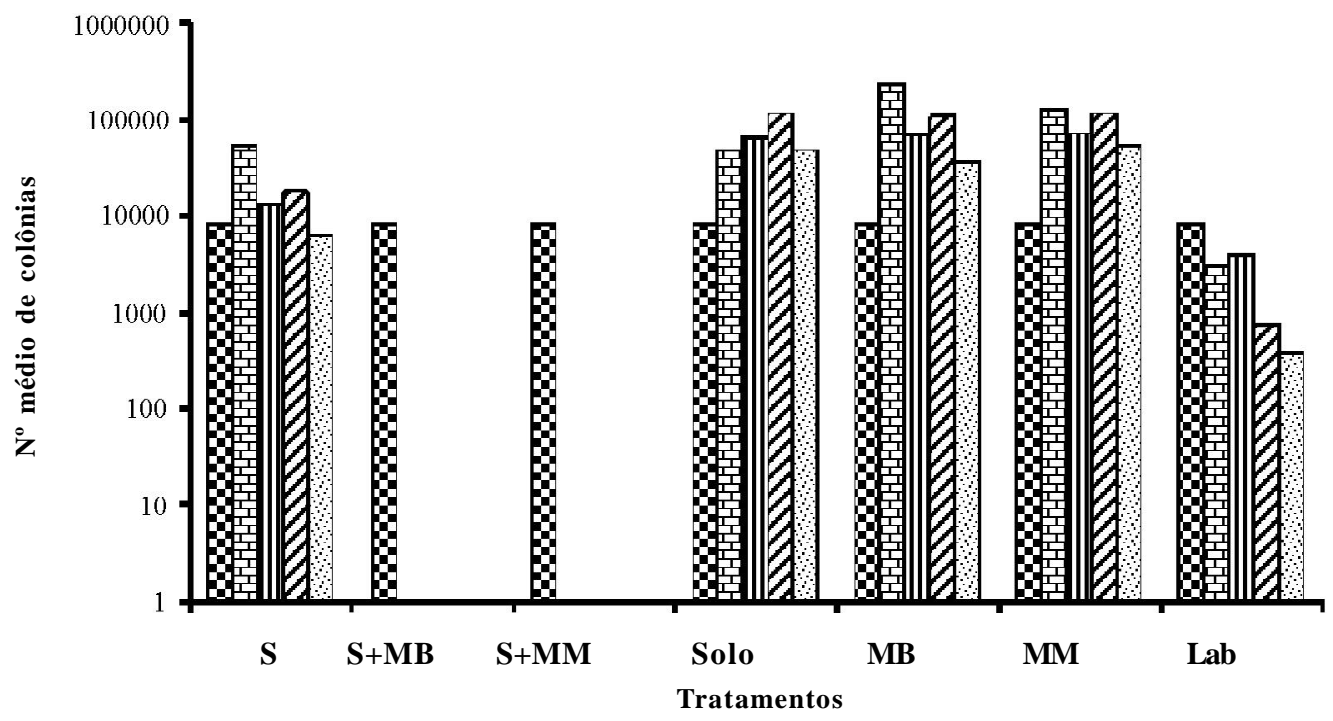

\begin{tabular}{lllll|l}
$\mathbf{E} 0$ & $\mathbf{E} 7$ & $\mathbf{U} 14$ & $\boldsymbol{\nabla} 21$ & $\mathbf{2} 28$ & Período de avaliaçao (em dias)
\end{tabular}

Figura 3: Sobrevivência de Fusarium oxysporum f. sp. lycopersici Raça 2 submetido a diferentes tratamentos e período de avaliação. S= Solarizado; MB = Mandioca brava; $\mathrm{MM}=$ Mandioca mansa; $\mathrm{Lab}=$ Laboratório. 
presente em larga quantidade neste material, atrelado a presença de outras substâncias, tais como cetonas, aldeídos, cianalaninas, lectinas e outras proteínas tóxicas, inibidoras de amilases e proteinases, apresentam grande eficiência como agentes fungicidas (20).

A mandioca brava segundo Lorenzi \& Dias (20), apresenta mais de $200 \mu \mathrm{g} / \mathrm{mL}$ de ácido cianídrico (HCN) em sua composição e a mandioca mansa menos de $100 \mu \mathrm{g} / \mathrm{mL}$ de $\mathrm{HCN}$, sendo que a última mostrou-se tão eficiente no controle do patógeno quanto a mandioca brava (2) (Figura 3). Assim, baixas concentrações do ácido podem ser suficientes para a inativação do patógeno estudado, caso venha a se comprovar em futuros estudos qual ser esse ácido o responsável pela inativação do fungo.

Os compostos orgânicos voláteis oriundos da decomposição da mandioca brava e mansa, possivelmente estão contribuindo de forma positiva para o controle de F. oxysporum f.sp. lycopersici Raça 2. Entretanto, não se sabe qual composto volátil é realmente o responsável pela toxicidade e inativação das estruturas de resistências deste patógeno, bem como em quais concentrações os mesmos comportamse como tóxicos ao fungo.

Certamente, muitos materiais orgânicos liberam gases tóxicos aos patógenos que quando não há cobertura plástica são facilmente perdidos para a atmosfera, não exercendo qualquer efeito de controle sobre os mesmos.

Este estudo demonstrou que a incorporação de mandioca brava e mansa seguida da solarização do solo inativou o $F$. oxysporum f.sp. lycopersici Raça 2 até o $7^{\circ}$ dia de experimento, mostrando que os dois materiais orgânicos apresentaram o mesmo potencial para erradicação do fungo estudado. Os demais tratamentos foram inócuos, permitindo a sobrevivência do fungo.

\section{AGRADECIMENTOS}

À Fundação de Amparo à Pesquisa do Estado de São Paulo (FAPESP) pela concessão da bolsa.

\section{REFERÊNCIAS BIBLIOGRÁFICAS}

1. Ambrósio, M. M. Q; Bueno, C. J; Padovani, C. R; Souza, N. L. De. Sobrevivência de fungos fitopatogênicos habitantes do solo, em microcosmo, simulando solarização com prévia incorporação de materiais orgânicos. Summa phytopathologica. Botucatu, v. 35, n.1, p. 20-25, 2009 .

2. Ambrosio, M. M. Q; Bueno, C. J; Padovani, C. R; Souza, N. L. De. Controle de fitopatógenos do solo com materiais vegetais associados à solarização. Summa phytopathologica. Botucatu, v. 34, n. 4, p. 354-358, 2008

3. Ambrósio, M. M. Q.; Bueno, C. J.; Padovani, C. R.; Souza, N. L. De. Efeito da incorporação de mandioca associada à solarização no controle de fitopatógenos do solo. Fitopatologia Brasileira, Botucatu, v.30, supl., p. 101, 2005.

4. Ambrósio, M. M. Q; Bueno, C. J.; Souza, N. L. Sobrevivência de Macrophomina phaseolina em solo incorporado com brócolos seguido de solarização. Summa Phytopathologica, Botucatu, v. 30, n. 3, p. 364-370, 2004.

5. Baptista, M. J; Souza, R.B; Pereira, W; Lopes, C. A; Carrijo, O. A. Efeito da solarização e biofumigação na incidência da murcha bacteriana em tomateiro no campo. Horticultura Brasileira, v. 24, n.2, p. 161-165, 2006. Brasília.

6. Basseto, M. A. Solarização em microcosmo: efeito de materiais vegetais na sobrevivência de fitopatógenos e na produção de voláteis. 2009. 79f. Tese (Doutorado)-Universidade Estadual Paulista "Júlio de Mesquita Filho", Faculdade de Ciências
Agronômicas, Campus de Botucatu.

7. Blok, W. J. Lamers, J.G., Termorshuizen, A.J., Bollen, G.J. Control of Soilborne Plant Pathogens by Incorporating Fresh Organic Amendmnets Followed by Tarping. Phytopathology, St. Paul, v. 90, n. 3, p. 253- 259, 2000.

8. Bokanga, M. Processing of cassava leaves for human consuption. Acta Horticultural, The Hague, v. 375, p. 203 -207, 1994.

9. Carvalho, V. D. ; Carvalho, J. G. Princípios tóxicos da mandioca. Informe Agropecuário, Belo Horizonte, v. 5, n. 59/60, p. 8288, 1979.

10. Curl, E. A. Control of plant diseases by crop rotation. The Botanical Review, v. 29, p. 413- 479, 1963.

11. Gamliel, A.; Stapleton, J. J. Characterization of antifungal volatile compounds envolved from solarizes soil amended with cabbage residues. Phytopathology, St. Paul, v.83, p. 899-905, 1993a.

12. Gamliel, A.; Stapleton, J. J. Effect of soil amendment with chicken compost or ammonium phosphate and solarization on pathogen control, rhizosphere microorganisms and lettuce growth. Plant Disease, St. Paul, v. 77, p. 886-891, 1993 b.

13. Ghini, R.; Schoenmaker, I. A. S.; Bettiol, W. . Solarização do solo e incorporação de fontes de matéria orgânica no controle de Pythium spp. Pesquisa Agropecuária Brasileira, Brasília, v. 37, n. 9, p. 1253-1261, 2002.

14. Ghini, R. Alternativas para substituir o brometo de metila na agricultura. Summa Phytopathologica, Jaboticabal, v. 27, n.1, p. 162, 2001.

15. Goulart, A. C. P. Benefícios do tratamento de sementes de algodoeiro com fungicidas no controle do tombamento em relação à densidade de inóculo de Rhizoctonia solani. Fitopatologia Brasileira, Brasília, DF, v. 27, Supl., p. 218, 2002.

16. Katan, J.; Vay, J.E. de. Soil solarization: historical perspectives, principles, and uses. In: Katan, J.; Vay, J.E. de (Ed.). Soil solarization. Boca Raton : CRC, 1991. p.23-37.

17. Katan, J.; Greenberger, A.; Alon, H.; Grinstein, A. Solar heating by polyethylene mulching for the control of diseases caused by soil-borne pathogens. Phytopathology, St. Paul, v. 66, p. 683688, 1976.

18. Komada, H. Development of a selective medium for quantitative isolation of Fusarium oxysporum from natural soil. Review of Plant Protection Research, Tokyo, v. 8, p. 114-124, 1975.

19. Lorenzi, J.O.; Dias, C.A. C. Cultura da mandioca. $2^{\text {a }}$ reimpressão. Boletim Técnico CATI, Campinas, n.211, 1993, 41p.

20. Ponte, J. J. Uso da manipueira como insumo agrícola: Defensivo e fertilizante. In: CEREDA, M. P. Manejo, uso e tratamento de subprodutos da industrialização da mandioca, Série culturas e tuberosas amiláceas Latino Americanas, Fundação Cargill. 2001, v. 6, p. 80-95.

21. Ramirez-Villapudua, J.; Munnecke, D. E. Control of cabbage yellows (Fusarium oxysporum f.sp. couglutinans) by solar heating of field soil amended with dry cabbage residues. Plant Disease, St. Paul, v. 78, p. 289-295, 1988.

22. Sivan, A.; Chet, I. Integrated control of Fusarium crown and root and root rot of tomato with Trichoderma harzianum in combination with methyl bromide or soil solarization. Crop Protection, Oxford, v. 12, p. 380-386, 1993.

23. Souza, N. L. De. Interação entre solarização e incorporação prévia de matéria orgânica no solo. Summa Phytopathologica, Botucatu, v. 30, n. 1, p. $142-145,2004$

24. Souza, N. L. de; Bueno, C. J. Sobrevivência de clamidósporos de Fusarium oxyzporum f. sp. lycopersici Raça 2 e Sclerotion rolfsii em solo solarizado incorporado com matéria orgânica. Summa Phytopathologica, Botucatu, v. 29, n. 2, p. 153 -160, 2003.

25. Souza, N. L. de. Sobrevivência de Fusarium oxyzporum f. sp. lycopersici e Sclerotium rolfsii em solo solarizado incorporado com matéria orgânica. 2001. 46 f. Tese (Livre Docência) - Escola Superior de Agricultura Luiz de Queiroz, Universidade de São Paulo, Piracicaba.

26. Wyllie, T. D.; Gangopadhyay, S.; Teague, W. R.; Blanchar, R. W. Germination and production of Macrophomina phaseolina microsclerotia as affected by oxygen and carbon dioxide concentration. Plant and Soil, Dordrecht, v. 81, p. 195-201, 1984. 